\title{
The Jerusalem Declaration on Ageing 2020 to share in English, Arabic and Hebrew
}

\author{
Sarah Harper ${ }^{1} \cdot$ Issi Doron ${ }^{2}$
}

Accepted: 2 August 2021 / Published online: 8 December 2021

(C) The Author(s) 2021

\begin{abstract}
The Anglo-Israel Colloquium in November 2019, Jerusalem, was a collaboration including Jewish and Arab-Israelis, Palestinians, and British participants arranged to drive forward the agenda for addressing inequalities within our populations as they age. This Colloquium brought together scholars, policy-makers, and service providers in the field of ageing from the UK and from Israel, in order to critically examine the societal effects and implications of both individual and population ageing. The following statement on ageing is the first result. Held up in its wider dissemination by the subsequent pandemic of 2020/2021, we are now delighted that the Jerusalem Declaration is now simultaneously published in Hebrew (Harper, S., \& Doron, I. (2021). The Jerusalem Declaration. Gerontology \& Geriatrics, 48(1), 113-116. [Hebrew]) and here in the Journal of Population Ageing in both English and Arabic.
\end{abstract}

Keywords Multi-Cultural perspectives $\cdot$ Inequalities $\cdot$ Population ageing

\section{The Jerusalem Declaration on Ageing 2020}

Contemporary human society faces unprecedented forces that will strongly effect the future. One major such force is the accelerated ageing of populations. This is driven by two interacting components: falling fertility leading to an increase in the average age of the population; and falling mortality, leading to an increase in the number and percentage of older adults, and in particular the oldest old.

However, different countries are at different stages of the ageing process: advanced ageing, with society already preparing for the impact of this demographic trend, but increasingly facing a growth in frail, dependent very old individuals; through to societies in the very early stages of demographic change combining the needs of younger people with those of older adults.

Sarah Harper

sarah.harper@ageing.ox.ac.uk

1 University of Oxford, Oxford, England

2 University of Haifa, Haifa, Israel 
The Anglo-Israel Colloquium provided an unique opportunity to address this spectrum. Our communities are in different stages on the population ageing process: advanced ageing in the UK, and the more diverse ageing processes among the respective sectors of Israeli society. Both countries thus reveal a spectrum of economic, social and health experiences across their diverse populations. There is a significant difference within the UK in both life expectancy and healthy life expectancy between the older populations living in Scotland, England, Wales and Northern Ireland, living within different regions in these countries, and within its various ethnic minority groups which now comprise around one fifth of the UK population. Similar variation is seen in Israel among and between various Jewish-Israeli populations, Jewish and Arab-Israelis, and with the Palestinian population.

This Colloquium brought together scholars, policy-makers, and service providers in the field of ageing from the UK and from Israel, in order to critically examine the societal effects and implications of both individual and population ageing. Drawing on the extensive debates and discussion made within the colloquium and in the following months, 10 key recommendations have been identified.

\section{Ten Recommendations: Jerusalem Declaration.}

\section{Ageing in the wider context.}

It should be recognised that population ageing does not occur in a vacuum, it is influenced by and in turn influences other global trends. Climate change is impacting upon older adults across the world in a specific manner due to their increased vulnerability which arises both from the ageing process itself, and the manner in which society constructs their societal position. Older people are particularly vulnerable to pandemics, as is evidenced by the current CV-19 pandemic.

\section{Ageing Policy in General}

Such population changes require a systemic and a life-course approach to policy making in response to population ageing, covering policy areas such as health, wellbeing, education, employment, and the built environment. Policy makers need to consider these changes across the life course in a more integrated fashion. Policies should aim to reduce the inequalities that arise from systematic differences in health, employment, and life expectancy between countries, between socio-economic groups, between women and men within countries, and between different ethnic, religious and cultural groups.

Access to education and health services, as well as facilitative learning, working and living conditions is the primary source of such inequality. Policies need to aim at reducing inequalities in these four areas.

Care of old people needs to be highly sensitive to their cultural characteristics and needs. In societies featuring multiple social, cultural and religious groups, it is essential to create an environment friendly and empathic to older adults, mindful 
of their religious, linguistic, and other preferences. This requires adequate training of personnel familiar with those requirements.

\section{Data \& Indicators}

3.1 Data on ageing populations require the development of additional indicators in order to improve social planning. Such indicators need to be sensitive to cohort changes in the ageing process, in particular to observed increases in physical and cognitive performance of older adults from cohort to cohort that seriously compromise the validity of chronological age as a marker of capacity or performance.

3.2 Large-scale longitudinal cohort-comparative surveys covering central domains of human functioning are required to support well-informed social planning. Inferences that are based on data from past cohorts run the risk of misinforming policy decisions.

\section{Work}

4.1 Longer lives suggest people need the choice to work longer. This will demand more flexible patterns over the life course. Policies should provide the institutional basis supportive of easier transitions between learning, working, and family life.

4.2 Retaining older people in the labour force calls for higher investments for continued training, and for maintaining general productivity. Related policies need to take into account rapidly changing working requirements, labour mobility, later retirement ages, and the greater need to combine work and retirement in a flexible manner.

4.3 High standards for the design of working environments need to be established which will enhance the working lives of all ages.

\section{Health}

5.1 A major policy aim should be to decrease the gap between life expectancy and healthy/disability-free life expectancy

5.2 Health systems need to combine the prevention of disease and disability with treatment for ill-health through expanding health-related resources across the life course.

5.3 The status of geriatric medicine and geriatric psychiatry needs to be raised to attract highly qualified younger practitioners.

\section{Formal \& Informal Care}

6.1 Formal and informal care is a valuable resource for society that too often falls as a burden on women without formal or financial recognition. Families who provide support and care for their elders should be recognized and provided with means and support. 
6.2 The increasing complexity of family forms, both at a given point in time and across the life course, requires flexible social policies. Reconciliation of family obligations and labour market demands must receive particular attention, as well as the redistribution of work and care between men and women, and between families, the state and the market.

6.3 A "caring economy" needs to be established and fully integrated into all societies which acknowledges the centrality of "reciprocal care" between and within generations, and which takes into account the costs and benefits of such care.

6.4 Training for informal care givers and primary care professionals is essential.

\section{Financial Security}

7.1 Old age pensions, both publicly and privately funded, need to be reassessed in order to secure social security and economic dignity in old age.

7.2 In an era of privatization, and a general movement toward fully funded, privately managed, defined-contribution pension schemes, the high-risks involved in such systems must be responded in an adequate regulatory and rights-based schemes to prevent poverty in old-age.

7.3 Pension equality is required to adjust pension disadvantage for women until the gender pay gap and labour force participation gap are both closed

\section{End of life care and decisions}

8.1 There is a need to re-examine end of life care, in particular with regards to developing and providing palliative care, as well as to give choice on when not to prolong life.

\section{Ageism \& Age Discrimination}

9.1 Ageism, the mostly negative social construction of old age, is a key determinant of the challenges older persons face in societies. Age-based discrimination and age bias must be recognised as harmful, and should be countered through adequate policies.

9.2 A pro-active policy approach, including raising public awareness,, educational programmes and intersectoral action in combating ageism is necessary for any social change.

\section{Design}

10.1 The importance of design should be recognised. Promoting the value of inclusive design of products, services, urban plans, housing, and communications is central to achieving greater social equity.

10.2 The role of participatory design, co-design and co-creation with older people, should be widely adopted to enable older adults to have more choice and control in how they live their lives. 
August 2020

• - س دقلا نال عا! :تايصوت رشع

•عسوألاقايسلايف ثخوخيشلا

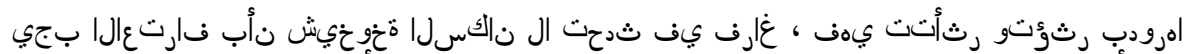

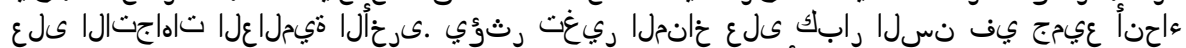

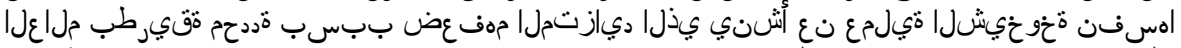

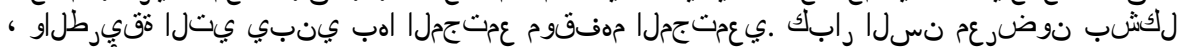

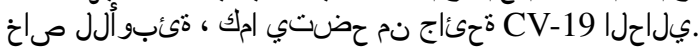

ماع لكشب تُخوخيشلاةسايس

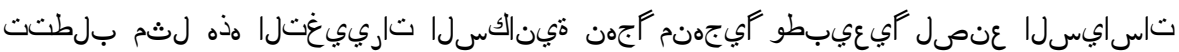

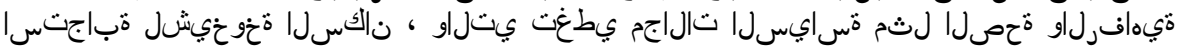

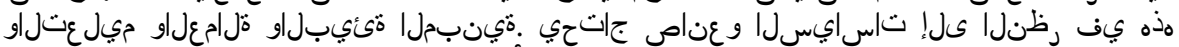

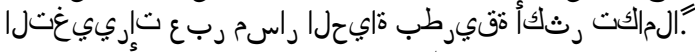

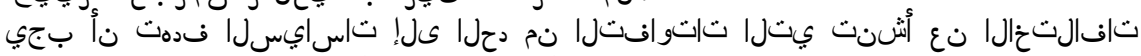

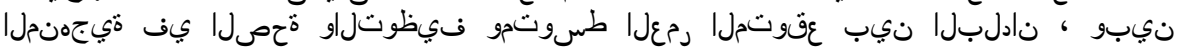

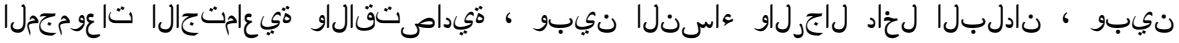

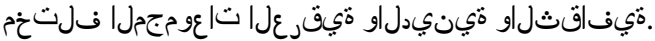

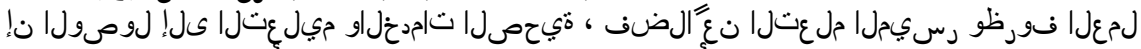

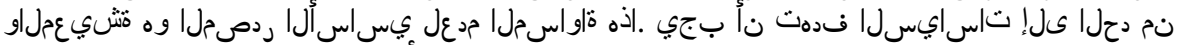

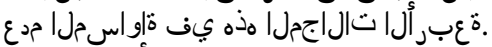

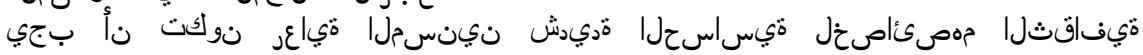

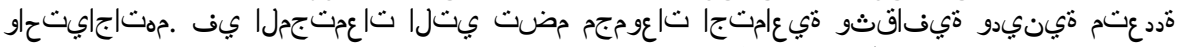

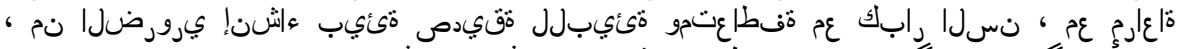

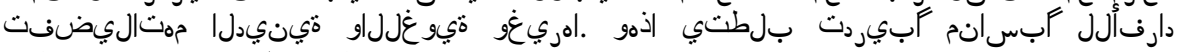

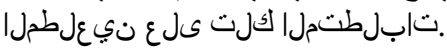

تارشؤملاو تانايبل

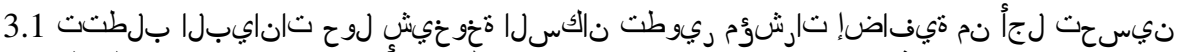

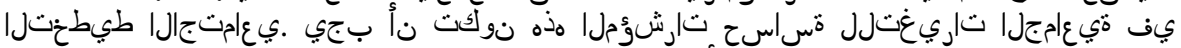

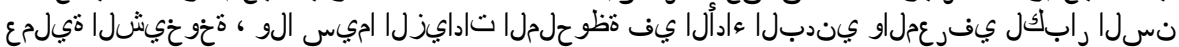

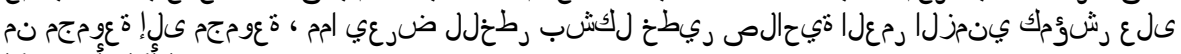

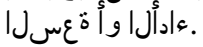

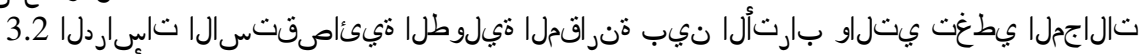

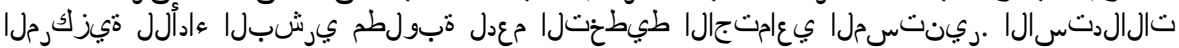

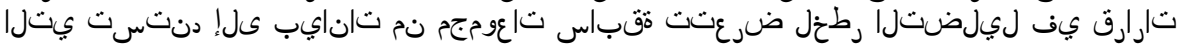
تس ايس 


\section{IJEJ}

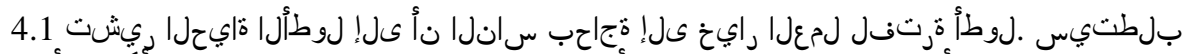

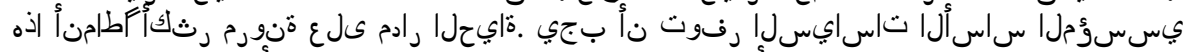

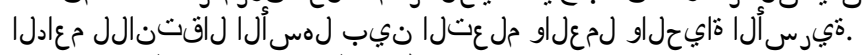

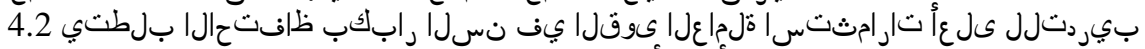

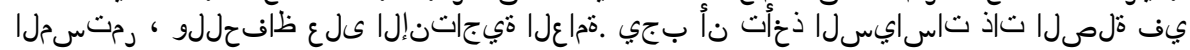

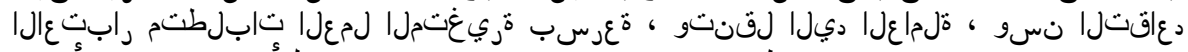

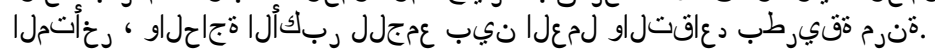

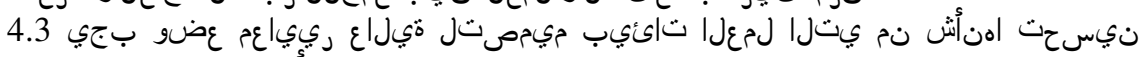

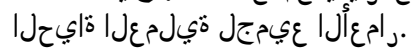

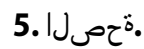

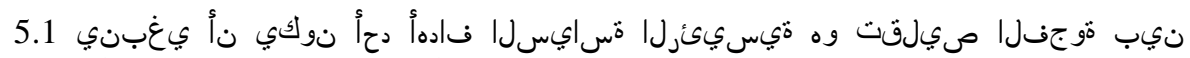

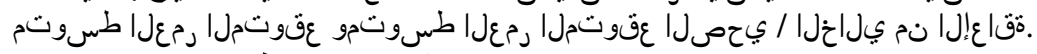

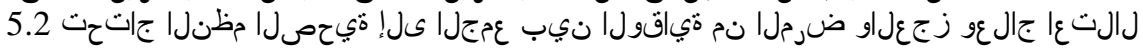

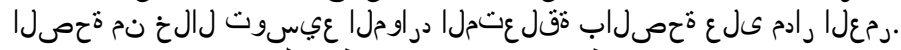

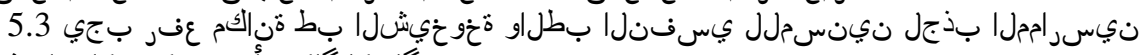

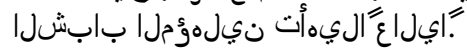

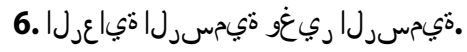

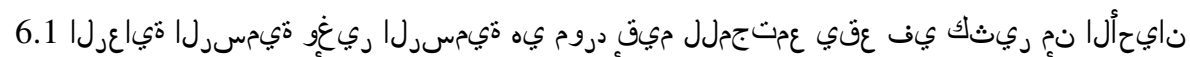

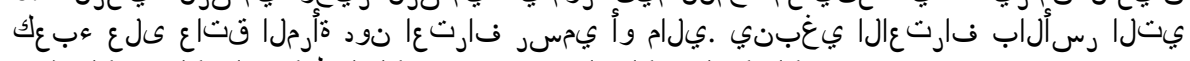

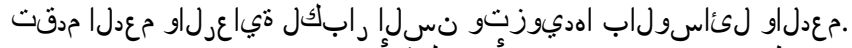

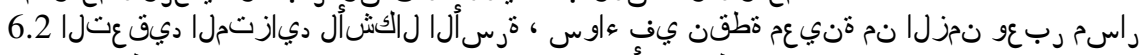

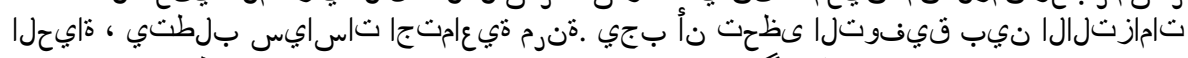

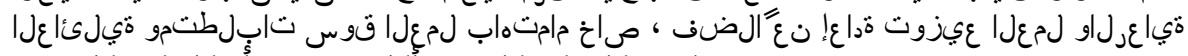

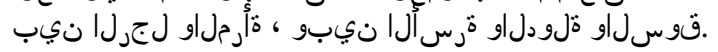

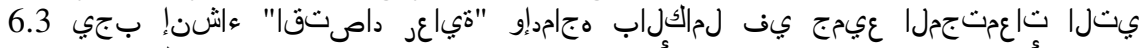

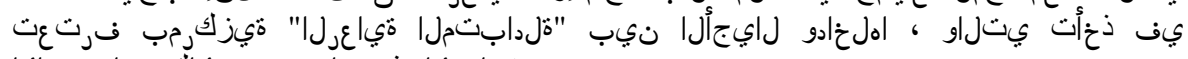

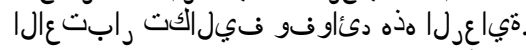

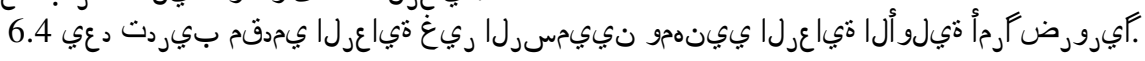

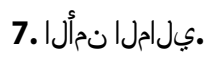

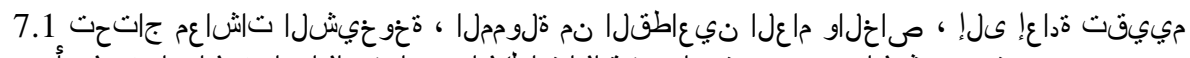
.

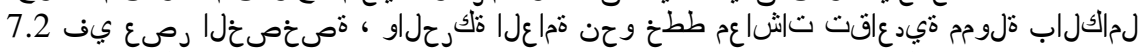

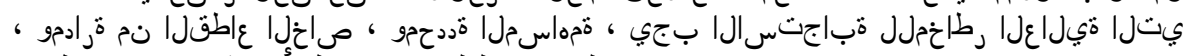

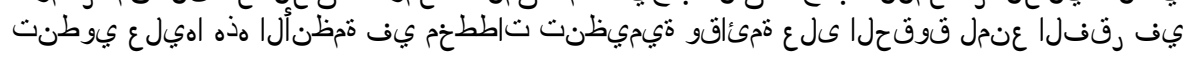

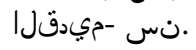




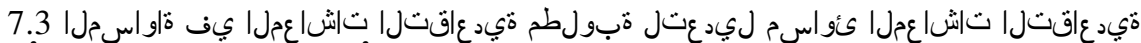

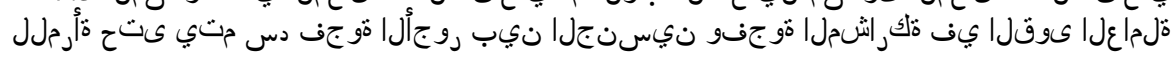

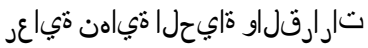

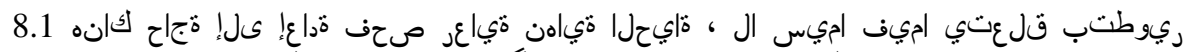

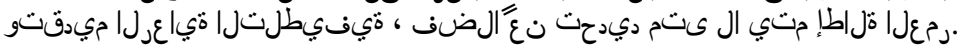

نسلاس ساس أىل زيبيجتلاو رمعل|

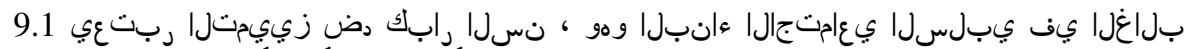

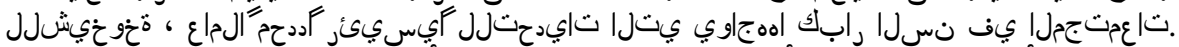

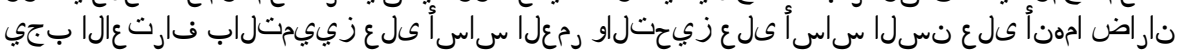

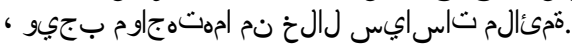

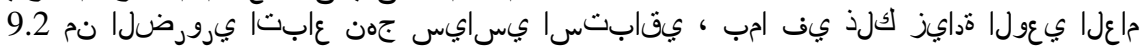

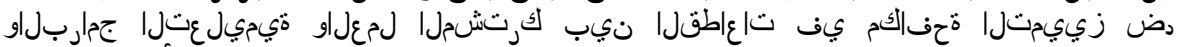
.

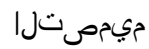

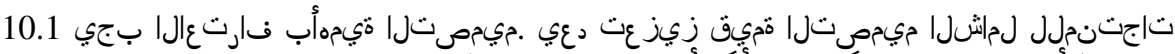

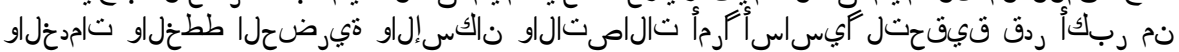

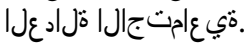

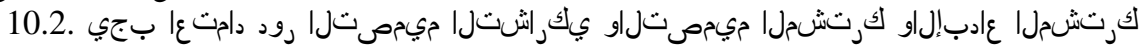

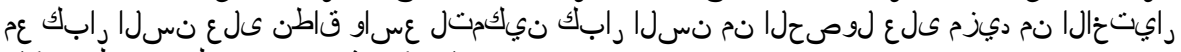

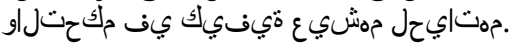

\section{Contributors to the Jerusalem Declaration 2020.}

Sarah Harper, University of Oxford.

Israel (Issi) Doron, University of Haifa.

Andrea Smokenevsky, UK Government Cabinet Office.

Andrei Martin PLP Architecture.

Daniel Gottlieb, National Insurance Institute, Isreal.

Frances Raday, Hebrew University, Jerusalem;

Galit Nimrod, Ben Gurion University.

Gill Livingston, University College London.

Hilary Salt, Institute of Actuaries, UK.

Ido Kallir, Ono Academic College, Israel.

Jennifer Rubin, UKRI ESRC UK.

Jeremy Myerson, Royal College of Art, London.

Ken Bluestone, Age International.

Liat Ayalon, Bar-Ilan University.

Lior Shtrassberg, MATAV - Community Services for Older Adults, Israel.

Mark Clarfield, Ben Gurion University.

Mohamed Ismail, University of Oxford.

Nick Hicks, CIRCO UK. 
Nurit Warftag, "Haaretz” Newspaper.

Pam Paled, Jerusalem Post.

Rivi Beller, "VeHadarta" - The Third Strength;

Samir Zoabi, Tel Hai Academic College;

Sara Carmel, Ben Gurion University.

Sasha Sidorenko, HelpAge.

Sergio Della Pergola, Hebrew University, Jerusalem.

Sylvia Parel-Leven, HelpAge.

Tom Wells, UK Government Office of Science.

Vered Solomon-Maman, Israel Ministry of Construction and Housing.

Yitzchak Brick, President Israeli Gerontological Society;

Yoval Palgi, University of Haifa.

Acknowledgement We are grateful to Dr Mohamed Ismail for his translation of the Declaration into Arabic.

Open Access This article is licensed under a Creative Commons Attribution 4.0 International License, which permits use, sharing, adaptation, distribution and reproduction in any medium or format, as long as you give appropriate credit to the original author(s) and the source, provide a link to the Creative Commons licence, and indicate if changes were made. The images or other third party material in this article are included in the article's Creative Commons licence, unless indicated otherwise in a credit line to the material. If material is not included in the article's Creative Commons licence and your intended use is not permitted by statutory regulation or exceeds the permitted use, you will need to obtain permission directly from the copyright holder. To view a copy of this licence, visit http://creativecommons.org/licen ses/by/4.0/.

Publisher's Note Springer Nature remains neutral with regard to jurisdictional claims in published maps and institutional affiliations. 